\title{
EVALUATION OF ALUMINIUM ALLOY SURFACE MACHINED BY MEANS OF ABRASIVE-FREE ULTRASONIC FINISHING
}

\author{
Sylvia Kuśmierczak ${ }^{1}$, Miroslav Müller ${ }^{2}$, Anatolii Lebedev ${ }^{3}$ \\ ${ }^{1}$ Jan Evangelista Purkyně University in Ústí nad Labem, Czech Republic; \\ ${ }^{2}$ Czech University of Life Sciences Prague; ${ }^{3}$ Stavropol State Agrarian University, Russia \\ kusmierczak@fvtm.ujep.cz,muller@tf.czu.cz, lebedev.1962@mail.ru
}

\begin{abstract}
Machining belongs to the basic technological operations in production companies. At present, research in ultrasonic machining has been in a progress, which is used as an effective finishing operation. This paper presents machining of the aluminium alloy by means of abrasive-free ultrasonic machining (A-FUM) with a discharge power $630 \mathrm{~W}$ and a frequency $22 \pm 2 \mathrm{kHz}$. The different cutting fluids containing nanoparticles were compared at the abrasive-free ultrasonic finishing. The roughness of the surface was evaluated by a microscope Olympus Lext within the research on the machined surface. The aim of other measurements was to evaluate the influence of the reviewed variants of the experiment on incidental reinforcement of the surface. Further, the machined surface was investigated from a hardness point of view. The hardness was measured by the method HBW2.5/62.5 on the surface. The surface and under-surface reinforcement was evaluated by means of the microhardness HV0.1. The machined surface was tested by means of the scanning electron microscopy (SEM) using a microscope TESCAN MIRA 3 GMX. A spectral analysis of the machined surface (EDX) was performed on the scanning electron microscope with the aim to detect residues of nanoparticles from the processing liquid in the surface.
\end{abstract}

Keywords: surface, ultrasonic finishing, aluminium alloys.

\section{Introduction}

Surface preparation is an important factor for practical application of machine components, particularly in situations such as the precise alignment and high strength applications [1]. It is necessary to pay attention to optimisation of the machining process [2-4].

At classical turning the surface comes into being, which has to be often further treated, e.g. by grinding. A reason is an unsuitable roughness of the surface [3].

The surface integrity is an essential property of machine parts. The state and properties of the machined surface are described by the surface integrity [5-7].

The major disadvantages of these processes are that they suffer from a low finishing rate and high equipment costs $[1 ; 8]$. Therefore, there is a need for an alternate process, which has the capability of nano-level finishing at higher finishing rate [8]. A possibility is to use ultrasonic finishing of the material. An improvement of the surface roughness compared to the abrasive finishing occurs at the use of the ultrasound $[2 ; 7 ; 8]$. The ultrasonic assisted abrasive flow machining is a new process in which the workpiece is subjected to ultrasonic vibration perpendicular to the medium flow [8] direction. The fundamental mechanism of the ultrasonic machining is material removal by means of the propagation of minute cracks that are inherently present [9] in such material. One of the possibilities of improving the machined surface quality is the method of abrasive-free ultrasonic finishing $[1 ; 2]$ of metals. This method is used namely as a finishing operation [2] after turning. The principle is based on generating of ultrasonic waving. The vibrating system deforms the surface layers of the machined part in a plastic way. This modified surface has a positive influence on friction, which is essential for practical application [10].

\section{Material and methods}

This research presents machining of aluminium alloy by means of abrasive-free ultrasonic machining (A-FUM) with the discharge power $630 \mathrm{~W}$ and the frequency $22 \pm 2 \mathrm{kHz}$. The secondary aim was to evaluate the influence of nano-particles contained in the cutting fluids.

The roughness of the surface was evaluated by a microscope Olympus Lext within the research on the machined surface. Further, the machined surface was investigated from a hardness point of view. The hardness was measured by the method HBW2.5/62.5 on the surface of the test samples in accordance with the standard ČSN EN ISO 6506-1. The test device (a small ball) of a mean $2.5 \mathrm{~mm}$ was loaded with a force $612.9 \mathrm{~N}$. 
The surface and under-surface reinforcement was evaluated by means of the microhardness according to Vickerse HV0.01 in accordance with the standard ČSN EN ISO 6507-1. The test device (a diamond pyramid) was loaded with a force $0.09807 \mathrm{~N}$. The microhardness was measured in the cut of the test samples, i.e. 25 to $875 \mu \mathrm{m}$ from the surface.

The machined surface was tested by means of the scanning electron microscopy (SEM) using the microscope TESCAN MIRA 3 GMX. A spectral analysis of the machined surface (EDX) was performed on the scanning electron microscope.

The tested material was aluminium alloy D16 GOST 4784-97. The chemical composition of the aluminium alloy (duralumin) is - $\mathrm{Al} 92.83 \%, \mathrm{Cu} 4.19 \%, \mathrm{Mg} 1.35 \%$, Si $0.19 \%$, Mn $0.72 \%, \mathrm{Zn}$ $0.22 \%$.

The tested material was machined by turning in the lathe at the variant 1 . It was treated by abrasive-free ultrasonic finishing with various cutting fluids (Fig. 1) after turning at other variants. The experiment variants are described below.

- Sample No. 1 - machining by turning, the cutting speed was $785 \mathrm{~mm} \cdot \mathrm{rev}^{-1}$, feed knives $0.04 \mathrm{~mm} \cdot \mathrm{rev}^{-1}$, cutting depth $0.5 \mathrm{~mm}$. The cutting fluid Avitol 2 was used during turning.

- Sample No. 2 - the same machining by turning was used as for the sample No. 1. The abrasive-free ultrasonic finishing was also used as the machining technology. Ultrasonic set I-4 was used for the research. The device with the discharge power $630 \mathrm{~W}$ and the frequency $22 \pm 2 \mathrm{kHz}$ was used for the research. The cutting speed was $40 \mathrm{~mm} \cdot \mathrm{rev}^{-1}$, feed rate $0.07 \mathrm{~mm} \cdot \mathrm{rev}^{-1}$.

- Sample No. 3 - the same machining was used as for the sample No. 2. A solution (nanopowder of $\mathrm{CuSn}$ in the layer 0.2 to $0.8 \mathrm{~mm}$ and industrial oil meet the standard GOST 7580-91) was applied during machining with the abrasive-free ultrasonic finishing technology.

- Sample No. 4 - the same the machining was used as for the sample No. 2. A solution (nanopowder of $\mathrm{CuNi}$ in the layer 0.2 to $0.8 \mathrm{~mm}$ and industrial oil meet the standard GOST 7580-91) was applied during the machining with the abrasive-free ultrasonic finishing technology.

- Sample No. 5 - the same machining was used as for the sample No. 2. A solution (nanopowder of $\mathrm{MoS}_{2}$ in the layer 0.2 to $0.8 \mathrm{~mm}$ and industrial oil meet the standard GOST 7580-91) was applied during the machining with the abrasive-free ultrasonic finishing technology.

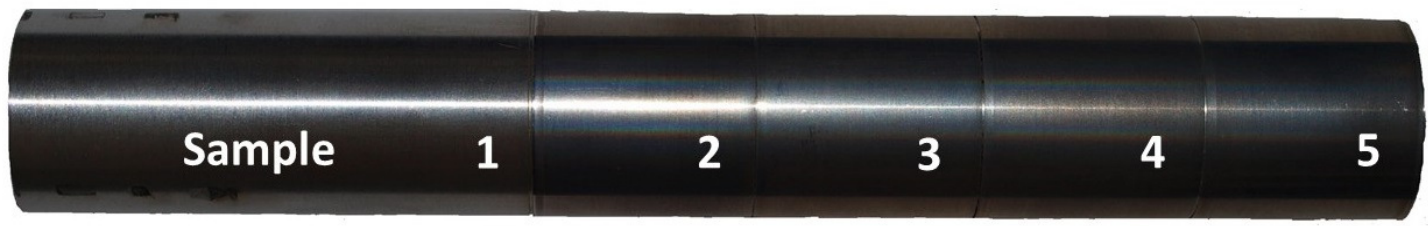

\section{Fig. 1. Test sample from aluminium alloy with single variants of machining}

The results of measuring were statistically analysed. Statistical hypotheses were also tested at the measured sets of data by STATISTICA software. The validity of the zero hypotheses $\left(H_{0}\right)$ showed that there was no statistically significant difference $(p>0.05)$ among the tested sets of data. In contrast, the hypothesis $H_{1}$ denied the zero hypotheses and showed that there was a statistically significant difference among the tested sets of data or dependence among the variables $(p<0.05)$.

\section{Results and discussion}

The graphical presentation of the results of the hardness HBW2.5/62.5 measured on the surface of the test samples is shown in Fig. 2. The results show that increased values of the surface hardness HBW2.5/62.5 are reached at the variants 2, 3, 4 and 5, i.e. with using of the abrasive-free ultrasonic finishing technology. The increase of the surface hardness HBW2.5/62.5 was in the interval 4 to $8 \%$. 
Statistical testing (Anova F-test) of the turned surface (the variant 1) and the abrasive-free ultrasonic finishing technology with the use of various nanoparticles in the cutting fluid (the variants 3,4 and 5) and the cutting fluid without the nanoparticles (the variant 2): all variants are statistically non-homogeneous groups, i.e. there is the difference in the surface hardness HBW2.5/62.5. The hypothesis $H_{0}$ was not certified, i.e. there is the difference in the hardness HBW2.5/62.5 in the significance level 0.05 among single tested variants 1 to 5, i.e. $p<0.05(p=0.000)$.

Statistical testing (Anova F-test) of the A-FUM technology with the use of various nanoparticles in the cutting fluid (the variants 3,4 and 5) and the cutting fluid without the nanoparticles (the variant 2): the variants 2, 3, 4 and 5 are statistically non-homogeneous groups, i.e. there is the difference in the surface hardness HBW2.5/62.5. The hypothesis $\mathrm{H}_{0}$ was not certified, i.e. there is the difference in the hardness HBW2.5/62.5 in the significance level among single tested variants 2 to 5, i.e. $p<0.05$ $(p=0.003)$.

In terms of the statistical testing of the abrasive-free ultrasonic finishing technology with the use of various nanoparticles in the cutting fluid (the variants 3,4 and 5) it is possible to say that they are statistically homogeneous groups, i.e. there is no difference in the surface hardness HBW2.5/62.5. The hypothesis $\mathrm{H}_{0}$ was certified, i.e. there is no difference in the hardness HBW2.5/62.5 in the significance level 0.05 among single tested variants 3 to $5, p<0.05(p=0.376)$. The influence of various nanoparticles in the cutting fluid on the surface hardness HBW2.5/62.5 was not statistically proved.

The hardness HBW2.5/62.5 on the surface was the highest at the variant 2, i.e. the A-FUM technology with the cutting fluid without nanoparticles.

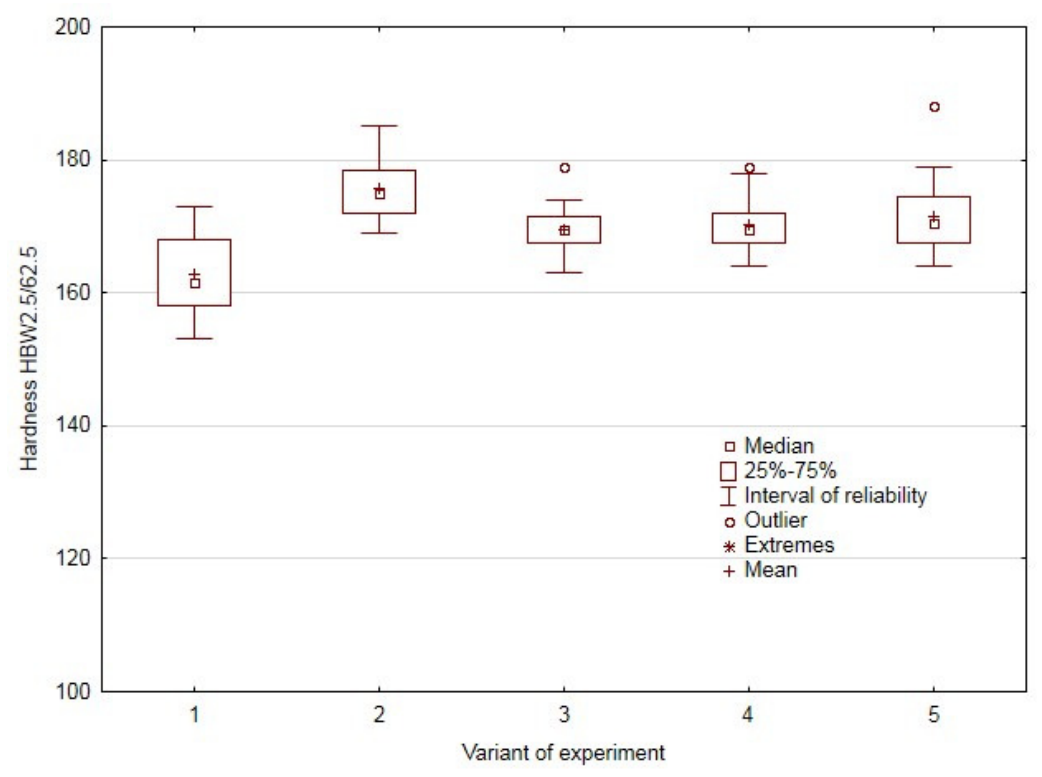

Fig. 2. Dependence of hardness HBW2.5/62.5 on the way of finishing

The graphical presentation of the results of the hardness HV0.01 measured in the longitudinal and transverse cut to the finished area of the test samples is shown in Fig. 3. The results show that increased values of the surface hardness HV0.01 are reached at the variants $2,3,4$ and 5, i.e. with using of abrasive-free ultrasonic finishing (various cutting fluids). The increase of the surface hardness HV0.01 was in the interval 5 to $11 \%$.

In terms of the statistical testing of the turned surface (the variant 1) and the abrasive-free ultrasonic finishing technology with the use of various nanoparticles in the cutting fluid (the variants 3,4 and 5) and the cutting fluid without the nanoparticles (the variant 2) it is possible to say that they are statistically non-homogeneous groups, i.e. there is the difference among the microhardness HV0.01 under the surface.

The hypothesis $H_{0}$ was not certified, i.e. there is the difference in the microhardness HV0.01 in the significance level 0.05 among single tested variants 1 to 5, i.e. $p<0.05$ (HV0.01 longitudinal direction $p=0.000$ and HV0.01 transverse direction $p=0.004$ ). 
In terms of the statistical testing of the abrasive-free ultrasonic finishing technology with the use of various nanoparticles in the cutting fluid (the variants 3,4 and 5) and the cutting fluid without the nanoparticles (the variant 2) it is possible to say that they are statistically homogeneous groups, i.e. there is no difference in the microhardness HV0.01 under the surface. The hypothesis $H_{0}$ was certified, i.e. there is no difference in the microhardness HV0.01 in the significance level 0.05 among single tested variants 2 to 5, i.e. $p<0.05$ (HV longitudinal direction $p=0.0635$ and HV0.01 transverse direction $p=0.5724$ ).

The influence of the abrasive-free ultrasonic finishing technology with the use of various nanoparticles in the cutting fluid (the variants 3,4 and 5) and the cutting fluid without the nanoparticles (the variant 2) on the microhardness HV0.01 under the surface of the aluminium alloy was not statistically proved.

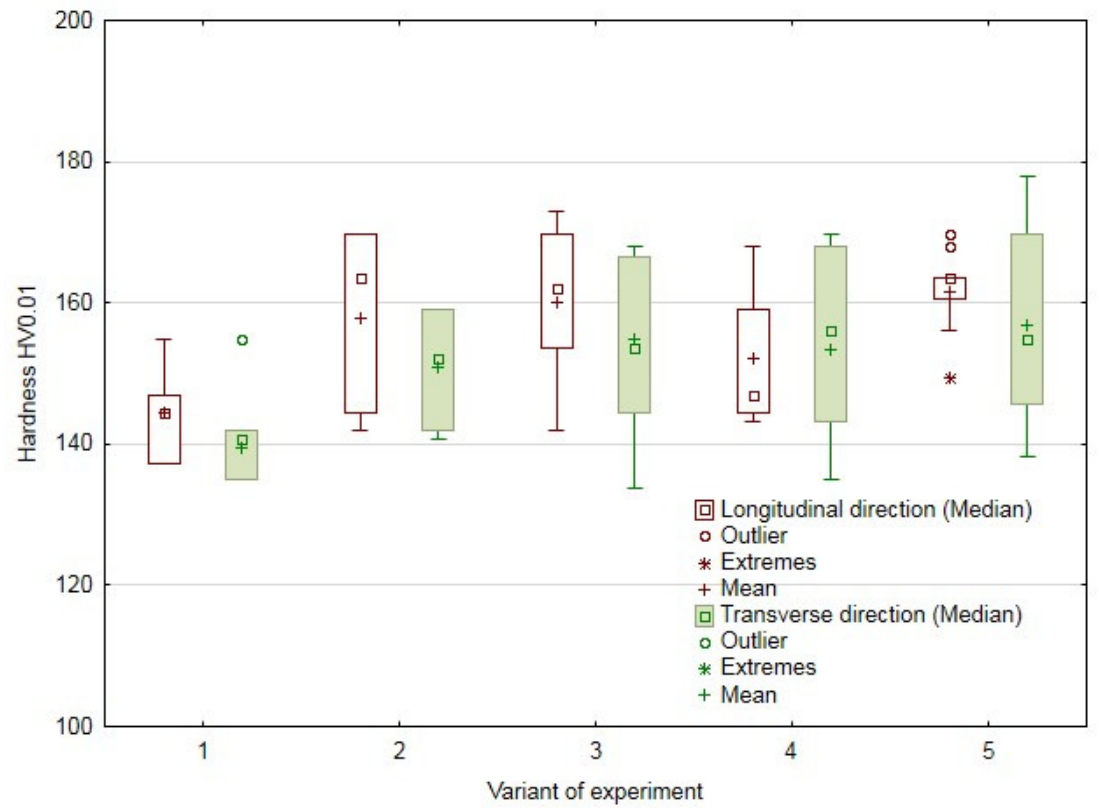

Fig. 3. Dependence of hardness HV0.01on the way of finishing

The graphical presentation of the hardness HV0.01 course measured in the longitudinal and transverse cut to the machined area of the test samples is shown in Fig. 4. The results in the interval 0 to $100 \mu \mathrm{m}$ under the surface of the machined area by various variants of the A-FUM technology showed more significantly higher values compared to the classical turning.

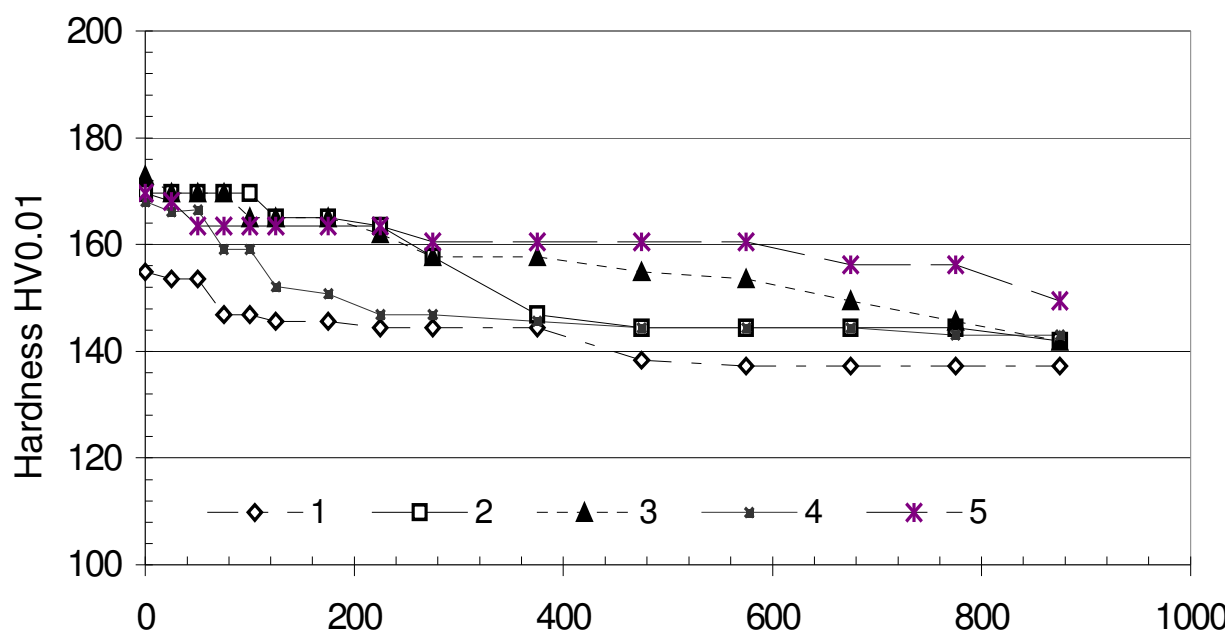

Distance from surface, $\mu \mathrm{m}$

Fig. 4. Dependence course of hardness HV0.01 on distance from the surface 
A graphical presentation of the surface roughness results is shown in Fig. 5 and 6. The results show that decreasing values of the surface roughness are reached at the variants $2,3,4$ and 5, i.e. with the use of the A-FUM technology.

In terms of the statistical testing of the turned surface (the variant 1) and the abrasive-free ultrasonic finishing technology with the use of various nanoparticles in the cutting fluid (the variants 3,4 and 5) and the cutting fluid without the nanoparticles (the variant 2) it is possible to say that they are statistically non-homogeneous groups, i.e. there is the difference among the surface roughness Ra and Rz. The hypothesis $\mathrm{H}_{0}$ was not proved, i.e. there is the difference in the surface roughness in the significance level 0.05 among single tested variants 1-5, i.e. $p<0.05\left(R_{a} p=0.001\right.$ and $\left.R_{z} p=0.000\right)$.

In terms of the statistical testing of the A-FUM technology with the use of various nanoparticles in the cutting fluid (the variants 3,4 and 5) and the cutting fluid without the nanoparticles (the variant 2) it is possible to say that they are statistically non-homogeneous groups, i.e. there is the difference among the surface roughness $R_{z}$. The hypothesis $H_{0}$ was not proved, i.e. there is the difference in the surface roughness $R_{z}$ in the significance level 0.05 among single tested variants $2-5$, i.e. $p<0.05(p=0.0168)$.

In terms of the statistical testing of the abrasive-free ultrasonic finishing technology with the use of various nanoparticles in the cutting fluid (the variants 3,4 and 5) and the cutting fluid without the nanoparticles (the variant 2) it is possible to say that they are statistically homogeneous groups, i.e. there is no difference in the surface roughness $\mathrm{Ra}$. The hypothesis $H_{0}$ was certified, i.e. there is no difference in the surface roughness $\mathrm{Ra}$ in the significance level 0.05 among single tested variants 2 to 5, i.e. $p<0.05(p=0.2936)$.

In terms of the statistical testing of the A-FUM technology with the use of various nanoparticles in the cutting fluid (the variants 3,4 and 5) it is possible to say that they are statistically homogeneous groups, i.e. there is no difference in the surface roughness $R_{a}$ and $R_{z}$. The hypothesis $H_{0}$ was certified, i.e. there is no difference in the surface roughness $\mathrm{Ra}$ and $\mathrm{Rz}$ in the significance level 0.05 among single tested variants 3 to 5, i.e. $p<0.05\left(R_{a} p=0.2712, R_{z} p=0.550\right)$. The influence of various nanoparticles in the cutting fluid on the surface roughness $\mathrm{Ra}$ and $\mathrm{Rz}$ was not statistically proved.

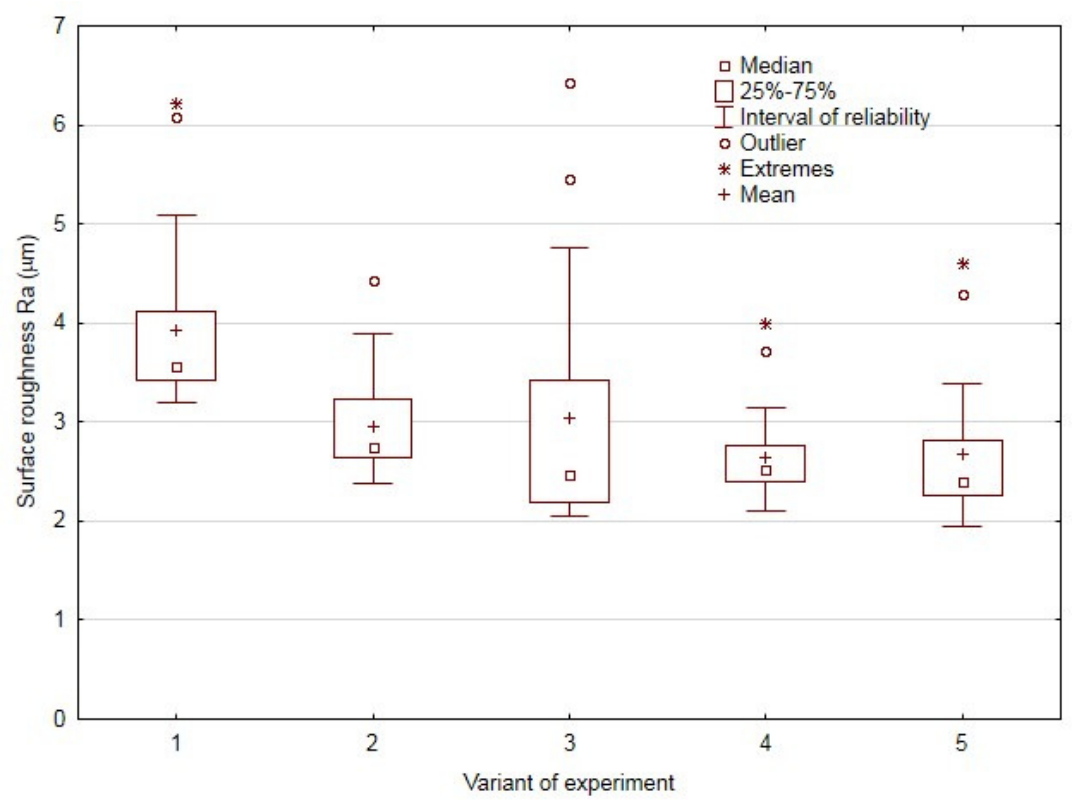

Fig. 5. Results of dependence of surface roughness $\boldsymbol{R}_{a}$ on the way of finishing (variant of the experiment)

The difference between the variant 1 , i.e. the classic turning and the variant 2 , i.e. the abrasivefree ultrasonic finishing is shown in Fig. 6. The change of the surface texture is obvious from SEM images. Also [11] came to analogous conclusions in his research on the surface after ultrasonic processing. 


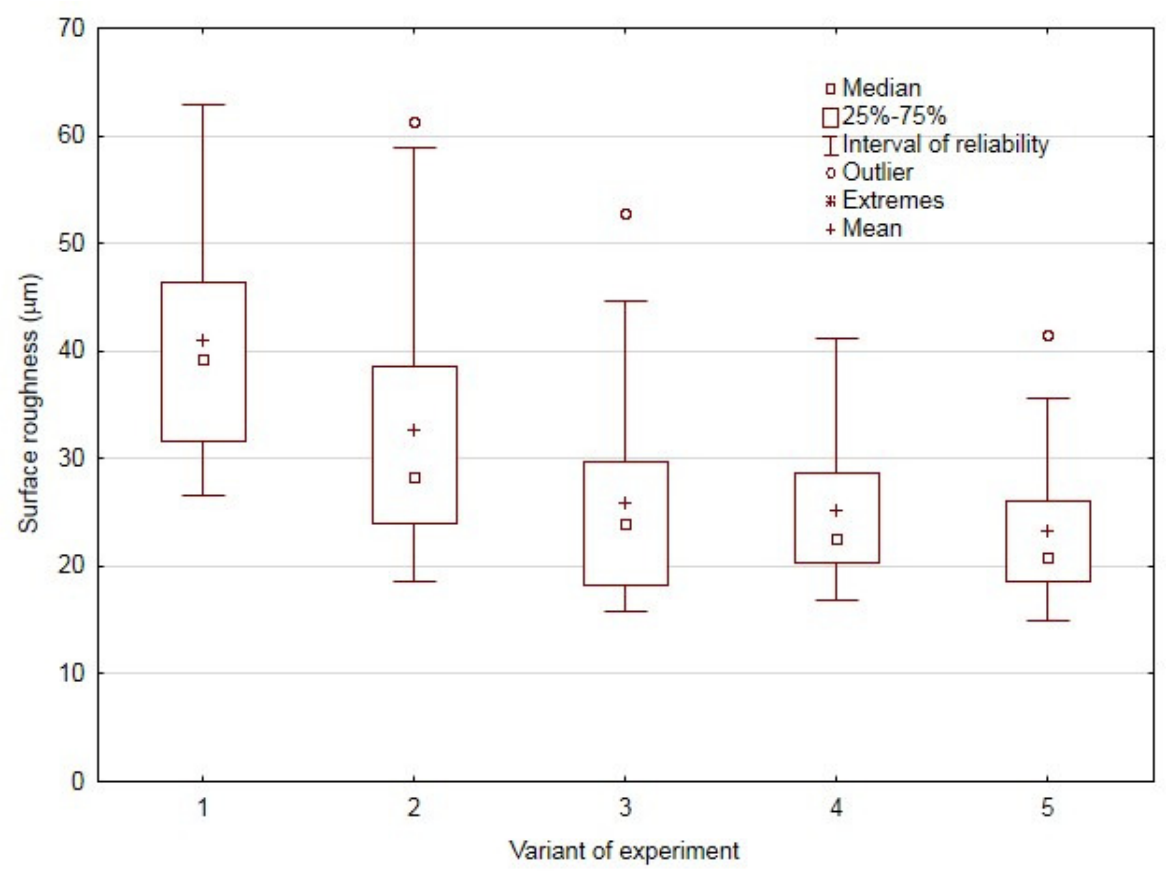

Fig. 6. Results of dependence of surface roughness $\boldsymbol{R}_{z}$ on the way of finishing (variant of the experiment)

Variants 2, 34 and 5 decrease the resultant $\mathrm{Ra}$ and $\mathrm{Rz}$ when using A-FUM for machining of aluminium alloy. Also other research studies $[1 ; 2 ; 9]$ came to the decrease of the roughness parameter by means of the ultrasonic method. The hardness on the surface and in the under-surface layers was also increased.
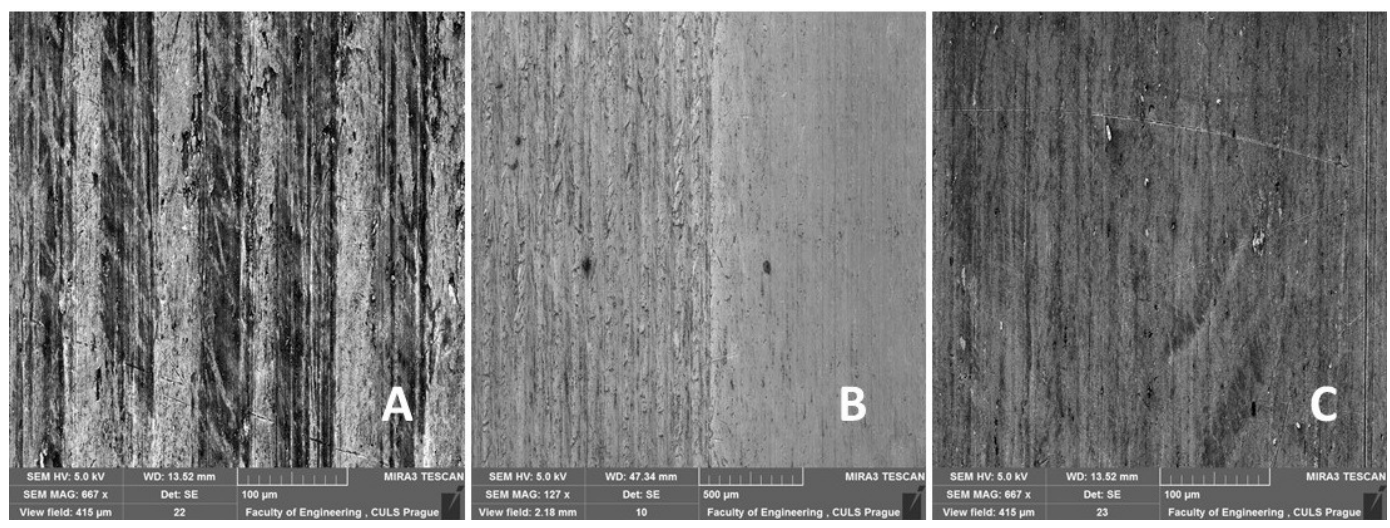

Fig. 6. SEM images of machined surface of aluminium alloy: A: variant 1 - turning (MAG $667 \mathrm{x}$, B: comparison of variant 1 (turning) and variant 2 (abrasive-free ultrasonic finishing) (MAG $127 \mathrm{x}$ ), C: variant 2 - abrasive-free ultrasonic finishing (MAG $667 \mathrm{x}$ )

The assumption was not certified that depositing of nanoparticles at the abrasive-free ultrasonic finishing enables:

- to decrease the surface roughness parameters $R_{a}$ and $R_{z}$,

- to increase the hardness on the surface and in the under-surface layers.

Also authors of other publications deduced analogous conclusions [12], i.e. the influence of nanoparticles on the improvement of the roughness parameters nor the increase of the hardness of the aluminium alloy.

The improvements of the surface parameters are described by Li et al. [13] in their study. However, they state the essentiality of the influence of different frequency on ultrasonic vibration.

This assumption was expected owing to another assumption that the surface micro-pores connected with the surface will be filled with these particles with additive industrial oil. The creation 
of the resistant microlayer was assumed owing to the mechanical acting of the working [12] head of the apparatus ultrasonic set I-4. The functional surface is very important for the practical application, it influences the total function of the device $[7 ; 11]$.

\section{Conclusions}

The hardness HBW2.5/62.5 on the surface was proved as the highest at the variant 2, i.e. the AFUM technology with the cutting fluid without nanoparticles.

It is obvious from the results that higher values of the surface hardness HBW2.5/62.5 are reached at the variants 2, 3, 4 a 5 than at the variant 1, i.e. with using of the A-FUM technology.

Increasing of the surface hardness HBW25 / 62.5 has been used in different variants of the AFUM technology with the cutting fluid with and without the nanoparticles.

The microhardness HV0.01 under the surface was increased at the abrasive-free ultrasonic finishing technology with the use of various nanoparticles in the cutting fluid (the variants 3,4 and 5) and the cutting fluid without the nanoparticles (the variant 2). The influence of the A-FUM technology with the use of various nanoparticles in the cutting fluid (the variants 3, 4 and 5) and the cutting fluid without the nanoparticles (the variant 2) on the microhardness HV0.01 under the surface of the aluminium alloy was not statistically proved.

The roughness parameters Ra and Rz were decreased at the A-FUM technology with the use of various nanoparticles in the cutting fluid (the variant 3,4 and 5) and the cutting fluid without the nanoparticles (the variant 2). The influence of various nanoparticles in the cutting fluid on the surface roughness $\mathrm{Ra}$ and $\mathrm{Rz}$ was not statistically proved.

The difference between turning (the variant 1) and the A-FUM technology is obvious from the results of the SEM analysis. The surface after the abrasive-free ultrasonic finishing technology is without significant inequalities.

\section{Acknowledgement}

The authors are grateful for the support of the grant EDIMARE CZ.1.05/4.1.00/11.0260.

\section{References}

1. Ales Z., Pavlu, J., Muller M., Svobodova J., Lebedev A., Yurov A., Pexa M., Linda M. Influence of abrasive - free ultrasonic finishing process of steel on wear. Manufacturing Technology, vol. 16(1), 2016, pp. 4-5.

2. Muller M., Lebedev A., Svobodova J., Naprstkova N., Lebedev P. Abrasive-free ultrasonic finishing of metals. Manufacturing Technology. vol. 14, 2014, pp. 366-370.

3. Naprstkova N., Kalincova D. Influence of additional chemical components on machining properties of selected aluminium - silicon alloy. 14th International Scientific conference: Engineering for rural development. May 20-22, 2015, Latvia Univ. Agr., Fac. Eng., Latvia, pp 766-771. ISSN: 1691-3043

4. Novak M. Surfaces with high precision of roughness after grinding. In: Manufacturing technology, vol. 12, 2012, pp. $66-70$.

5. Holesovsky F., Naprstkova N., Novak M. GICS for grinding process optimization. Manufacturing technology, vol. 12, 2012, pp. 22-26.

6. Pa P.S. Super finishing with ultrasonic and magnetic assistance in electrochemical micromachining. Electrochimica Acta, Vol. 54, 2009, pp. 6022-6027.

7. Ruggiero A., D'Amato, Merola M. Experimental comparison on tribological pairs UHMWPE/TIAL6V4 alloy, UHMWPE/AISI316L austenitic stainless and UHMWPE/AL2O3 ceramic, under dry and lubricated conditions. Tribology International, vol. 96, 2016, 349-360.

8. Venkatesh G., Sharma A. K., Kumar P. On ultrasonic assisted abrasive flow finishing of bevel gears. International Journal of Machine Tools and Manufacture, vol. 89, 2015, pp. 29-38.

9. Curodeau A., Guay J., Rodrigue D., Brault L., Gagne D., Beaudioin L.P. Ultrasonic abrasive $\mu$ machining with thermoplastic tooling. International Journal of Machine Tools \& Manufacture, vol. 48, 2008, pp. 1553-1561. 
10. Ruggiero A, D'Amato, Merola M., Valasek P., Muller M. Tribological characterization of vegetal lubricants: Comparative experimental investigation on Jatropha curcas L. oil, Rapeseed Methyl Ester oil, Hydrotreated Rapeseed oil. Tribology International, vol. 109, 2017, pp. 529-540.

11. Zhang Qinjiana, Cao Jianguoa, Wang Huiyinga. Ultrasonic Surface Strengthening of Train Axle Material 30CrMoA, 18th CIRP Conference on Electro Physical and Chemical Machining (ISEM XVIII), Procedia CIRP 42. 2016, pp. 853-857.

12. Ruggiero A., Merola M., Carlone P., Archodoulaki V. M. Tribo-mechanical characterization of reinforced epoxy resin under dry and lubricated contact conditions. Composite Part B: Engineering. vol. 79, 2015, pp. 595-603.

13. Li G., Qu S.G., Pan Y.X., Li X.Q., Effects of the different frequencies and loads of ultrasonic surface rolling on surface mechanical properties and fretting wear resistance of HIP Ti-6Al-4V alloy, Applied Surface Science, vol. 389, 2016, pp. 324-334. 